October 1997

\title{
Pneumonia perceptions and management: an ethnographic study in urban squatter settlements of Karachi, Pakistan
}

Rafat Hussain

Aga Khan University

Melvyn A. Lobo

Aga Khan University

Bazmi Inam

Aga Khan University

Amanullah Khan

Aga Khan University, amanullah.khan@aku.edu

Asma Fozia Qureshi

Aga Khan University, fozia.qureshi@aku.edu

See next page for additional authors

Follow this and additional works at: https://ecommons.aku.edu/pakistan_fhs_mc_chs_chs

\section{Recommended Citation}

Hussain, R., Lobo, M. A., Inam, B., Khan, A., Qureshi, A. F., Marsh, D. (1997). Pneumonia perceptions and management: an ethnographic study in urban squatter settlements of Karachi, Pakistan. Social Science and Medicine, 45(7), 991-1004.

Available at: https://ecommons.aku.edu/pakistan_fhs_mc_chs_chs/529 
Authors

Rafat Hussain, Melvyn A. Lobo, Bazmi Inam, Amanullah Khan, Asma Fozia Qureshi, and David Marsh 


\title{
PNEUMONIA PERCEPTIONS AND MANAGEMENT: AN ETHNOGRAPHIC STUDY IN URBAN SQUATTER SETTLEMENTS OF KARACHI, PAKISTAN
}

\author{
RAFAT HUSSAIN*, MELVYN A. LOBO, BAZMI INAM, AMANULLAH KHAN, \\ ASMA FOZIA QURESHI and DAVID MARSH \\ Department of Community Health Sciences, Aga Khan University, Karachi, Pakistan
}

\begin{abstract}
Childhood pneumonia continues to be the second highest contributor to childhood morbidity and mortality in all ethnic groups in Pakistan. Information on community perceptions and management is largely limited to the Punjabi populace. In this study, ethno-specific illness terminologies, recognition and severity indicators and resort to treatment options for childhood pneumonia are explored among the two main ethnic groups in Sindh. Results are based on focus group discussions with 90 caretakers and 16 case history interviews. The findings indicate that pneumonia recognition is almost universal. The main recognition and severity indicator was pasli chalna (chest indrawing) followed by signs and symptoms relating to the quality of breathing and presence of high fever, lethargy and anorexia. Recognition of rapid breathing was low and mostly associated with fever. Exposure to thand (cold) through a variety of mechanisms was perceived to be the dominant causal model. The concept of contagion was virtually non-existent. Despite this, belief in efficacy of allopathic care was very high. Most caretakers reported seeking outside care within one to three days of the onset of symptoms. However, unrealistic expectations of cure often led to change in physicians and treatment regimen, if no improvement was observed by the second day. On the other hand, the quality of care provided by the physicians (both licensed and unlicensed) left much to be desired. Female autonomy and mobility did not appear to be a major constraint in seeking outside care other than for hospitalisation. Implications of these findings for the national acute respiratory infections control programme and future research are discussed 1997 Elsevier Science Ltd
\end{abstract}

Key words-childhood pneumonia, maternal perceptions, medical anthropology, Pakistan

\section{INTRODUCTION}

Pakistan has witnessed a steady decline in child mortality in the past two decades (UNICEF, 1994; Ahmed et al., 1992). Nonetheless, acute respiratory infections (ARI), particularly acute lower respiratory tract infections (ALRI), continue to be the second highest contributor to childhood morbidity and mortality (Aga Khan University, 1991a; 1992; Ahmed et al., 1992; Zaman et al., 1993; Khan et al., 1993; Marsh et al., 1993). To date there is paucity of published studies from Pakistan describing socio-anthropological perceptions of ARI and related health seeking behaviour. Information from published literature is limited to: a couple of community-based studies in the northern part of Punjab (Mull and Mull, 1994; Rehman et al., 1994), with one of them (Mull and Mull, 1994) providing lim-

*Author for correspondence.

†In response to the National ARI Control Programme, the Department of Community Health Sciences of the Aga Khan University developed an ARI training programme for its primary health care (PHC) operations. The training programme was aimed at improving maternal knowledge of pneumonia as well as training of all cadres of the PHC staff followed by targeting of health care providers in the community. ited information from some squatter settlements of Karachi; and two hospital-based studies in Rawalpindi in Punjab province (Kundi et al., 1993: Mull et al., 1994).

Although these studies provide valuable information about maternal perceptions and management of pneumonia, they are largely limited to the Punjabi population in Pakistan. The sample covered by the community-based study for Karachi was a convenience sample with very few Sindhi and Mohajir respondents (one and four, respectively). the two main ethnic groups in Sindh province. It is. therefore, difficult to predict whether the research findings of the above studies are generalisable to these ethnic groups. The focus of this paper is thus to provide information on local ethno-specific terminologies, perceptions of illness causation and symptomatology, and illness management practices of pneumonia among Sindhis and Mohajirs. through a qualitative study undertaken in 19921993. Secondary objectives of the study were to refine a large prospective quantitative study on ALRI as a first step towards developing an ARI training programme. $\dagger$ 


\section{EVIDENCE FROM THE DEVELOPING WORLD}

There exists a considerable pool of scientific information on pneumonia aetiology, risk factors and effective low cost antimicrobial treatment (Selwyn, 1990; WHO, 1990; Bang et al., 1990; Tapasi et al., 1990; Vathanopass et al., 1990). Recent years have also seen a great upsurge of interest in ethnographic studies, especially after the development of the World Health Organisation's (WHO's) FES (Focused Ethnographic Study) guidelines (WHO, 1993). These studies on ALRI from four continents provide invaluable cross-cultural information on language-specific illness terminology, maternal perceptions of disease aetiology, physical signs and symptoms and illness coping strategies. The findings of some of the larger and more relevant studies are briefly reviewed here in order to place the findings of the present paper in their proper context.

\section{Illness recognition}

In general pneumonia was recognised by most of the caretakers, although there was a great variation in the recognition of specific features. Early pneumonia signs such as rapid breathing were by and large not picked up by caretakers (de Tejada, 1990; Nichter and Nichter, 1994; Stewart et al., 1994; Dyal and Bhattacharyya, 1994), however, research in Gambia, Egypt, Indonesia and Pakistan (Gittelsohn et al., 1991; Godomski et al., 1992; Kresno et al., 1994; Mull et al., 1994) shows that caretakers, especially those with past experience, did recognise rapid breathing, but often did not report it unless specifically asked. The main reason for this discrepancy was that rapid breathing was not considered dangerous and mothers were, therefore, more inclined to report signs and symptoms that they considered were either causing distress to the child, such as excessive cough, difficult and noisy breathing, irritability or/and those that alarmed the mother such as fever, chest indrawing, refusal to feed and lethargy. In particular, in almost all the studies mothers focused on fever and often the duration of illness was marked by the number of days of fever or change in the intensity from low to high grade fever (Nichter and Nichter, 1994).

\section{Disease aetiology}

There were remarkable similarities in maternal perceptions of pneumonia causation in most of the studies (de Tejada, 1990; Gittelsohn et al., 1991; Mull and Mull, 1994; Nichter and Nichter, 1994; Dyal and Bhattacharyya, 1994; Kresno et al., 1994), which are totally at variance with the biomedical disease model. Almost all cited exposure to cold through a variety of mechanisms, e.g. climatic changes, hot cold imbalance, exposure to cold in a lactating mother, ingestion of foods considered to be cold, as the main cause of the illness. ALRI was mostly considered to be a progression of URI (upper respiratory tract infection), and in some cases apportioning blame to maternal neglect was common (Stewart et al., 1994; Hudelson, 1994). Perceptions of supernatural forces giving evil eye did not appear to be too dominant, except for pneumonia among newborns in Bolivia (Charaly, 1992) and to some extent in Bangladesh (Stewart et al., 1994). Pneumonia was generally not considered contagious, although belief in cure through allopathic medicines was moderately high.

\section{Illness management}

Most studies report home treatment in the initial stages. Detrimental practices such as chest binding were reported to be a common practice in only a few studies (Wilson and Kimane, 1990; Godomski et al., 1992). Although there appeared to be a general consensus on the efficacy of allopathic care, the timing was varied with many studies reporting delay in seeking care from clinics and hospitals. The reasons for the delay were either related to constraints at the home level such as lack of money, limited female autonomy and mobility (Nichter and Nichter, 1994) or experimentation with over the counter drugs, mainly antibiotics (Stewart et al., 1994; Dyal and Bhattacharyya, 1994; Kresno et al., 1994) or reluctance to take very young infants (Nichter and Nichter, 1994; Hudelson, 1994) to health care facilities because of mothers' undue protectiveness.

\section{BACKGROUND INFORMATION ON STUDY SITES}

Karachi is the largest industrial city of Pakistan with an estimated population of 12 million, $40 \%$ of which reside in squatter settlements. These settlements are areas of low income, poor sanitation, overcrowding, and inadequate health services with a heavy burden of disease morbidity and mortality.

The two settlements selected for this study were Chanesar Goth and Orangi. The main rationale for selecting these settlements was that they each had a major ethnic group of interest, and were part of the Aga Khan University's urban primary health care (PHC) programme. In addition to a PHC centre, both the settlements have at least half a dozen private practitioner clinics, a few of which operate throughout the day and the rest for four to five hours in the evenings. Chanesar Goth is a 200 years old settlement with a predominantly Sindhi population. The main language is Sindhi although most of the population does understand Urdu (the official language). Most of the Sindhi inhabitants of Chanesar Goth retain close familial links with rural areas of Sindh, especially through marriages; thus its population is a mix of urban and rural Sindhis. The settlement is located close to the business and commercial centre of the city, and has the added advantage of close proximity to a large public hospital. The second settlement was Orangi with a pre- 
dominantly Mohajir (descendants of migrants from Northern India) population, whose language is Urdu. The Mohajirs not only differ from the Sindhis linguistically, but also have very different cultural values which have been shaped by years of urban living and relatively much higher literacy levels. Orangi is physically somewhat isolated from the main city, hence its inhabitants have more limited choice in health care services. It does, however, have a small public hospital nearby and through it, links to another government tertiary hospital.

The PHC programme was established in Orangi and Chanesar Goth in 1985 and 1987, respectively, and consisted of both preventive/promotive and curative health care services.* Baseline health status obtained through surveys conducted in the two study areas showed very little difference except for ethnicity (Karim, 1987). Within each study area, the PHC programme covered a population of approximately 10,000 people. The infant mortality rate was over 100 per thousand live births in both the settlements. However, within Chanesar Goth there was a much larger disparity in the health status due to the presence of some extremely disadvantaged population subgroups. The mean monthly family income was Rs 1600 (U.S.\$40). Although female literacy was generally very low, the rates were comparatively better in Orangi than in Chanesar Goth. The mean family size was eight and the mean number of rooms per family were 1.5 . Most of the men in both the settlements were employed as daily wage earners, often in menial jobs, which required them

*At the time of the study, the urban PHC programme was functional in five squatter settlements of Karachi and covered over 50,000 population. The PHC infrastructure in each settlement was a three-tiered pyramidal system comprising a team of Community Health Workers, Lady Health Visitors and Community Doctors and Nurses operating from a communitybased PHC centre. All families were registered with the programme and were visited on a monthly basis for growth monitoring, identification of risk factors (e.g. incomplete or lack of immunisation. promotion of ORS/breast feeding) and health education. All relevant family vital records were updated on a monthly basis. Curative care was provided at the PHC centre (with the clinics open every day between $9 \mathrm{a} . \mathrm{m}$. and $3 \mathrm{p} . \mathrm{m}$.) with back up referral care at either the Aga Khan University Hospital or major public tertiary care facilities. The entire PHC programme was monitored through a management information system based on information contained in the family folders and morbidity profiles maintained at the PHC centre.

†Pilot testing was done in three non-study sites to assess the feasibility of using audio-visual material and tape recording of sessions at the community level. Results showed that the use of video attracted a large number of children who proved to be a major source of distraction for the mothers participating in group discussions. It was, therefore, decided during the actual group discussions, to run a popular video film in a separate room for the children. This approach, though somewhat costly, proved to be extremely successful. to be away for the greater part of the day, whereas the majority of the women were housewives.

The overall under five child mortality statistics from the five urban programmes (inclusive of Orangi and Chanesar Goth) showed a proportionate mortality ratio of $10 \%$ due to pneumonia in the two years preceding the study (Aga Khan University, 1990; 1991b).

\section{METHODOLOGY}

An ethnographic study was conducted in these two squatter settlements over a four month period (November 1992-February 1993). Two qualitative research methods, namely focus group discussions and case history interviews, were used sequentially to explore maternal beliefs and practices regarding pneumonia. The reason for using two different research methods was mainly to gain an understanding of the gaps between hypothetical and real life perceptions and coping mechanisms. Another reason, though less important, was to gain familiarity with local illness terminologies and management through group discussions before undertaking case history interviews and to allow the seasonal peak of ALRI to set in (late December/January), thus increasing the number of ALRI cases for case history interviews. Verbal consent was obtained from the study respondents before scheduling any discussion sessions or interviews.

The methodology employed for focus group discussions involved use of selected sections of the WHO video on ARI. $\uparrow$ Two segments of the video depicting a child suffering from pneumonia and exhibiting signs of rapid breathing and chest indrawing were shown. The sound track was switched off to control response bias that may have occurred with mothers possessing elementary knowledge of the English language; however, this may in turn have led to some mothers missing out on cues provided by sounds of grunting, wheezing and other noises. The video clippings were followed by listing of illness terminologies and discussion on key recognition features, severity indicators, possible causal pathways, family decision-making dynamics and resort to treatment. The discussions were recorded both with the help of notes and tape recordings. The use of tape recorders was readily agreed to once their use for facilitating note taking and more accurate data analysis had been explained to participants and, surprisingly, did not lead to any inhibitions in expression of opinions and participation in the discussions. All the focus group discussions were conducted in the local language by the Principal Investigators (PIs) to ensure accuracy and consistency. Notes taken by the research assistants (sociologists by training) were matched with tape recordings and detailed transcripts were prepared in the local language by the PIs. These tran- 
scripts were subsequently translated by the PIs into English.

Thirteen focus group discussion sessions were conducted, six in Chanesar Goth with Sindhi women and seven in Orangi with Mohajir women. To make the results representatives of the two ethnic groups in these settlements, the target population was divided into geographically contiguous clusters each containing 100-150 households. Within each cluster, the selection of child caretakers was based on ethnic affiliation and the presence of at least one surviving child under five years of age in each household. Each focus group was composed of six to eight mothers, and the results are based on the responses of 90 participants who attended the focus group discussions. The mean age of the Sindhi and Mohajir respondents was 34 and 29 years, respectively. Over two-thirds were illiterate and the remaining third had schooling of one to five years - a few in Orangi had secondary education. The mean number of children was 5.5 among Sindhi women, and close to 4.0 among Mohajir women.

Sixteen sets of case history interviews were conducted with primary caretakers of children under five years of age reported to have pneumonia. Each interview had a follow-up visit after one week of the initial visit in order to assess the disease outcome and resort to treatment options. Since not many children with pneumonia were brought to the PHC health centre, assistance was sought from private physicians working in the study areas to identify pneumonia cases. Nonetheless, there were fewer reported cases of pneumonia compared to the previous year, which was mainly attributed to the very mild winter in Karachi during the study year. All cases $(n=5)$ occurring in households of focus group participants were excluded from the case history interview sample. A semistructured field guide was used to elicit maternal perceptions of key recognition and severity features of the illness, concepts of causation and management strategies. All the interviews were conducted by the authors, and were recorded, in addition to notes taken by research assistants. Transcripts in local language and translations into English were done by the PIs in a manner similar to those of the focus group sessions.

\section{RESULTS}

\section{Terminology}

The most commonly used term (among $70 \%$ of the focus group participants) to describe the illness depicted in the video was pasli chalna (chest indrawing). A large number of mothers also said numonia or double numonia. Some mothers said that the child had sardi or thand (cold). On further probing it was revealed that sardi and thand were used syno- nymously or interchangeably for numonia. Another common term used to describe pneumonia was saans (breathing). The term saans, however, had wider meaning, including presence of either tez saans (rapid breathing), saans mey mushkil (respiratory difficulty); at times it was also used to describe duma (asthma). The term tez saans was not only limited to numonia but was also reported for conditions such as khansi (cough), bukhar (fever), sookhey kee beemari (dried up illness, mostly like marasmus), kamzori (weakness/undernutrition) and duma (asthma). A substantial number of mothers said that the child had sookhey kee beemari (marasmus). Other commonly mentioned illnesses were pet kee kharabi/takleef (upset stomach/stomach ache) and ulti-julab (vomiting and diarrhoea) leading to pani kee kami (dehydration). With the exception of two sessions, in all other groups the term numonia was reported without any prompting.

All the child caretakers $(n=16)$ in the case history interviews used the term numonia to describe the illness. Some mothers $(n=6)$ described the illness as double numonia. Some of the Sindhi caretakers also used the terms sardi and thand to describe pneumonia, whereas some of the Mohajir respondents used the more general term saans kee beemari (respiratory illness) to describe pneumonia.

Overall, most of the ALRI disease terminology was similar in both the ethnic groups. However, within the Sindhi community, an array of terms for pneumonia (Table 1) were found. Moreover, a number of terms were used interchangeably to describe asthma and pneumonia.

Table 1. ARI-related illness terminology among Sindhi and Mohajir child caretakers in urban squatter settlements of Karachi

\begin{tabular}{|c|c|c|}
\hline English & Sindhi & Urdu \\
\hline Pneumonia & $\begin{array}{c}\text { Numonia } \\
\text { Thadra }^{\mathrm{a}} \\
\text { Jheta }^{\mathrm{a}} \\
\text { Sardi/Thand } \\
\text { Dum Kashi }\end{array}$ & $\begin{array}{c}\text { Numonia } \\
\text { Thand } \\
- \\
-\end{array}$ \\
\hline Severe pneumonia & Double numonia & $\begin{array}{c}\text { Double numonia } \\
\text { Bohat zayada numonia }\end{array}$ \\
\hline Pertussis & $\begin{array}{c}\text { Kali khansi } \\
\text { Karthea }\end{array}$ & Kali khansi \\
\hline Chest indrawing & $\begin{array}{c}\text { Pasli chalna } \\
\text { Pasli baithna } \\
\text { Jhar ho jana } \\
\text { Hadiyan hilan pavion }\end{array}$ & $\begin{array}{c}\text { Pasli chalna } \\
\text { Pasli lagna } \\
\text { _- }\end{array}$ \\
\hline Asthma & $\begin{array}{c}\text { Duma } \\
\text { Saans } \\
\text { Dum Kaashi }\end{array}$ & $\begin{array}{l}\text { Duma } \\
\text { Saans }\end{array}$ \\
\hline Sputum/Phlegm & $\begin{array}{l}\text { Bulgum } \\
\text { Raysha } \\
\text { Jaala }\end{array}$ & $\begin{array}{c}\text { Bulgum } \\
-- \\
-\end{array}$ \\
\hline Measles & $\begin{array}{l}\text { Lori mata } \\
\text { Khasra }\end{array}$ & $\begin{array}{c}\text { Khasra } \\
-\end{array}$ \\
\hline Typhoid fever & Taephoed & Taephoed \\
\hline
\end{tabular}

"Specific Sindhi terminology;

'used interchangeably for asthma and/or respiratory diseases. 


\section{Sign and symptom recognition}

Caretakers were asked about the physical signs and symptoms that led them to think that the illness was pneumonia. The most commonly reported (unprompted) recognition feature of pneumonia was pasli chalna. Other terms used by Sindhi mothers for chest indrawing included pasli baithna, jhar ho jana and hadiyaan hilan pavion (all implying movement of the ribs). In contrast, the Urdu terminology for chest indrawing was limited to pasli chaina and pasli lagna. When mothers were probed to explain the meaning of pasli chalna, the explanations were rapid movement of the ribs, ribs moving in and out, and khadda (recession) below the ribs or in the abdomen. Most mothers associated pasli chalna with pneumonia. Additional common recognition features include seenay mey kharkharhat (chest noise), seena bund (blocked/quiet chest), aggravation of nazla, zukham, khansi (runny nose, cold, cough), and continuing fever coupled with baichainee (heightened irritability/restlessness) as a manifestation of numonia. Some mothers considered the combination of ulti-julab (vomiting and diarrhoea) and pasli chalna as a manifestation of onset of numonia.

Rapid breathing was mentioned (without prompting) by only a handful of Mohajir mothers and by only one Sindhi mother. When prompted, most caretakers associated rapid breathing with fever rather than pneumonia. Also there appeared to be some confusion regarding the type of breathing in pneumonia. A number of caretakers in the group discussions felt that respiration was slower and more labourious in pneumonia which they termed as saans khainch key laina (laboured breathing) and lambey saans (deep breathing).

All the case history interview caretakers $(n=16)$ reported that the child was suffering from numonia. In over two-thirds of the cases (11 of the 16 cases), the diagnosis was made by the mother herself prior to consultation with a health care provider. The key recognition features (unprompted) for pneumonia are presented in ranked order in Table 2. Pasli chalna was reported as the key recognition feature by over half of the respondents. Rapid breathing (tez saans) was mentioned by less than a quarter of caretakers. Other important recognition features included saans mey mushkil (difficult breathing) and bulgum (phlegm/sputum) also called raysha in Sindhi.

\section{Stages in disease progression}

Most caretakers reported that pneumonia developed as a result of exacerbation in the symptoms of URI (nazla, zukham). Cough became worse (more frequent, turned productive), sputum changed from clear to green and/or became difficult to expectorate and breathing became more noisy. The combination of green sputum and noisy breathing was considered to be manifestations of cold trapped in the chest (thand seenay may baith jaana). In a few instances, mothers considered pneumonia to manifest in the initial stages as ulti-julab (vomiting and diarrhoea), with green coloured stools indicating that thand (cold) was trapped in the body. Caretakers reported becoming alarmed when there was an increase in fever, especially when it was combined with a lack of appetite, irritability (manifested by excessive crying or inability to sleep at night) and/or lethargy. Similar findings of fever being the central focus of maternal reporting have been reported by Mull $e t$ al. (1994) in their work at Rawalpindi General Hospital as well as by Nichter and Nichter (1994) in the Philippines.

\section{Perceived illness severity}

Most mothers considered numonia and double numonia as potentially fatal conditions. The most commonly cited indicator of severe illness was pasli chalna. Other indicators were continuous or increasing bukhar (fever), refusal to feed and lethargy termed kamzori or girnay lagta hai. As one mother said "I... do not worry when my children have cough and cold, but the moment they have bukhar [fever] I start worrying... when there is pasli chalna [chest indrawing] and/or saans mey mushkil [difficult breathing]...I know the illness is khatarnak [life threatening]...". Some mothers also considered a combination of high grade fever and lethargy as indications that bukhar damagh per char gaya hai (fever has reached the brain) which too was con-

Table 2. Key recognition features (unprompted) of pneumonia among Sindhi and Molajir child caretakers in urban squatter settlements of Karachi

\begin{tabular}{|c|c|c|c|c|}
\hline \multirow{2}{*}{$\begin{array}{l}\text { Recognition feature (local } \\
\text { term) }\end{array}$} & \multirow[t]{2}{*}{ Literal translation } & \multirow{2}{*}{$\begin{array}{c}\text { Approximate biomedical } \\
\text { term }\end{array}$} & \multicolumn{2}{|c|}{ No. of respondents } \\
\hline & & & $n$ & $\%$ \\
\hline Pas/i chalna & Movement of ribs & Chest indrawing & 9 & 56.3 \\
\hline Tez Saans & Rapid breathing & Rapid breathing & 3 & 18.8 \\
\hline Saans mushkil & Difficult breathing & Difficult breathing & 3 & 18.8 \\
\hline Bulgum/Raysha & Sputum & Phlegm & 3 & 18.8 \\
\hline Bhook marna & Lack of appetite & Anorexia & 2 & 12.5 \\
\hline Seena bund & Closed chest & Chest congestion & 2 & 12.5 \\
\hline Saans hara hara & Deep breathing & Laboured breathing & 1 & 6.3 \\
\hline Saans may kharkharahat & Noisy breathing & Noisy breathing/grunting & 1 & 6.3 \\
\hline Bohat rona & Excessive crying & Irritability & 1 & 6.3 \\
\hline
\end{tabular}

"Total greater than $100 \%$ due to multiple responses. 
Table 3. Key indicators of illness severity of pneumonia among Sindhi and Mohajir child caretakers in urban squatter settlements of Karachi

\begin{tabular}{|c|c|c|c|c|}
\hline \multirow{2}{*}{ Indicators } & \multirow[t]{2}{*}{ Literal translation } & \multirow{2}{*}{$\begin{array}{l}\text { Approximate biomedical } \\
\text { term }\end{array}$} & \multicolumn{2}{|c|}{ No. of respondents } \\
\hline & & & $n$ & $\%$ \\
\hline Pasli chalna & Movement of ribs & Chest indrawing & 7 & 43.8 \\
\hline Bohat haichaines & Heightened irritability & Irritability & 3 & 18.8 \\
\hline Seena bund & Closed chest & Chest congestion & 2 & 12.5 \\
\hline Bohat zayada khansi/thand & Excessive cough/cold & Exacerbation of URI ${ }^{\mathrm{b}}$ & 1 & 6.5 \\
\hline Girnay lagna & Lethargy & Lethargy & 1 & 6.5 \\
\hline Tez bukhar & High fever & High grade fever & $i$ & 6.5 \\
\hline Demag per bukhar & Drowsiness & Drowsiness & 1 & 6.5 \\
\hline Tez saans & Rapid breathing & Rapid breathing & 1 & 6.5 \\
\hline Bhook khatam & Lack of appetite & Anorexia & 1 & 6.5 \\
\hline
\end{tabular}

"Total greater than $100 \%$ due to multiple responses;

'URI = upper respiratory infection.

sidered a potentially life threatening situation. Nasal flaring (nathne phoolna) was only mentioned by one caretaker as a severity indicator. There was some disagreement amongst the focus group participants regarding the meaning of the terms numonia and double numonia. While some reported these terms to be synonymous, others considered them as separate entities. The distinction was mainly attributed to severity of illness. An increase in pasli chalna (chest indrawing), tez saans (rapid breathing) leading to breathlessness, abdominal distension and increase in fever were the commonly agreed upon terminologies to describe double numonia.

Information from case history interviews (Table 3) showed that the key indicator for severity of illness was pasli chalna (chest indrawing) followed by bohat baichainee (very restless) and seena bund (blocked chest). None of the caretakers reported rapid breathing (in isolation) as a severity indicator as the general perception was that an increase in respiratory rate was caused by fever. The following quote from one of mothers typifies most of the responses of most child caretakers:

...the child had halki khansi [mild cough] for one week, and then she developed bukhar [fever]. Within the same day the fever increased... and the child started to have pasli chalna [chest indrawing] and also tez saans [fast breathing]... I immediately took her to a doctor [allopathic] and he confirmed my suspicion that nazla seeney pe jam gaya hai [chest congestion] which is what numonia is all about.

This is true also of many other studies (Gittelsohn et al., 1991; Mull et al., 1994; Nichter and Nichter, 1994; Kresno et al., 1994) where the researchers found that caretakers gave priority to communicating those symptoms that they considered best described the child's (or perhaps the mother's) distress and what Mechanic (1962) labels as "ticket of admission". Most caretakers reported seeking outside care for fever and apparent listlessness of the child, than for any other perceived severity indicator. In fact the single most commonly used criterion for judging improvement in the child's condition was bukhar may kamee (lowering of fever).

\section{Causality concepts}

Almost all the causes mentioned were related to exposure to thand (cold) through a variety of mechanisms (Fig. 1). Humoral imbalance caused by ingestion of cold foods in particular during the winter was the most commonly mentioned cause. Another popular belief, more common in the Sindhi population, is the transmission of thand through breast milk in situations where a lactating mother either eats foods that have a cold effect, or exposes herself to thand by coming in contact with water for certain household chores such as washing clothes "... after washing clothes one evening, I breast fed my child, soon after my cold milk got into his body, he started having pasli chalna [chest indrawing] and started moon nochna [literally scratching the face and implying restlessness]... I knew there and then that the thand from my body had led to numonia in my child". Similar to this notion is the belief among Mohajir women of catching thand (chill), also termed as sardi by children playing with water or bathed with cold water especially during the winter or evening time in summer "after playing in the sun all day, careless mothers bathe their children in the evenings, and dress them in bareek [fine/ light] clothes and let them be exposed to cold air from the fan... what else do they expect if not numonia from all this garam/sard [hot-cold] exposure". Under-nourished children and children with pre-existing URI were considered to be more at risk of developing numonia through this mechanism. It appears that such causality concepts are not limited to any particular geographic area as similar findings have been reported from places such as the Philippines, Bangladesh, Guatemala and Ghana (Nichter and Nichter, 1994; Stewart et al., 1994; de Tejada, 1990).

Most caretakers did not consider numonia to be caused by nazar (evil eye); however, there were more Sindhi women inclined to consider the influence of supernatural forces in protracted or complicated pneumonia cases. Conditions in which nazar may be at play were reported to be sookhey kee beemari (marasmus), khoon kee kami (anaemia), sust tabeyat (lethargy) and refusal to feed. 


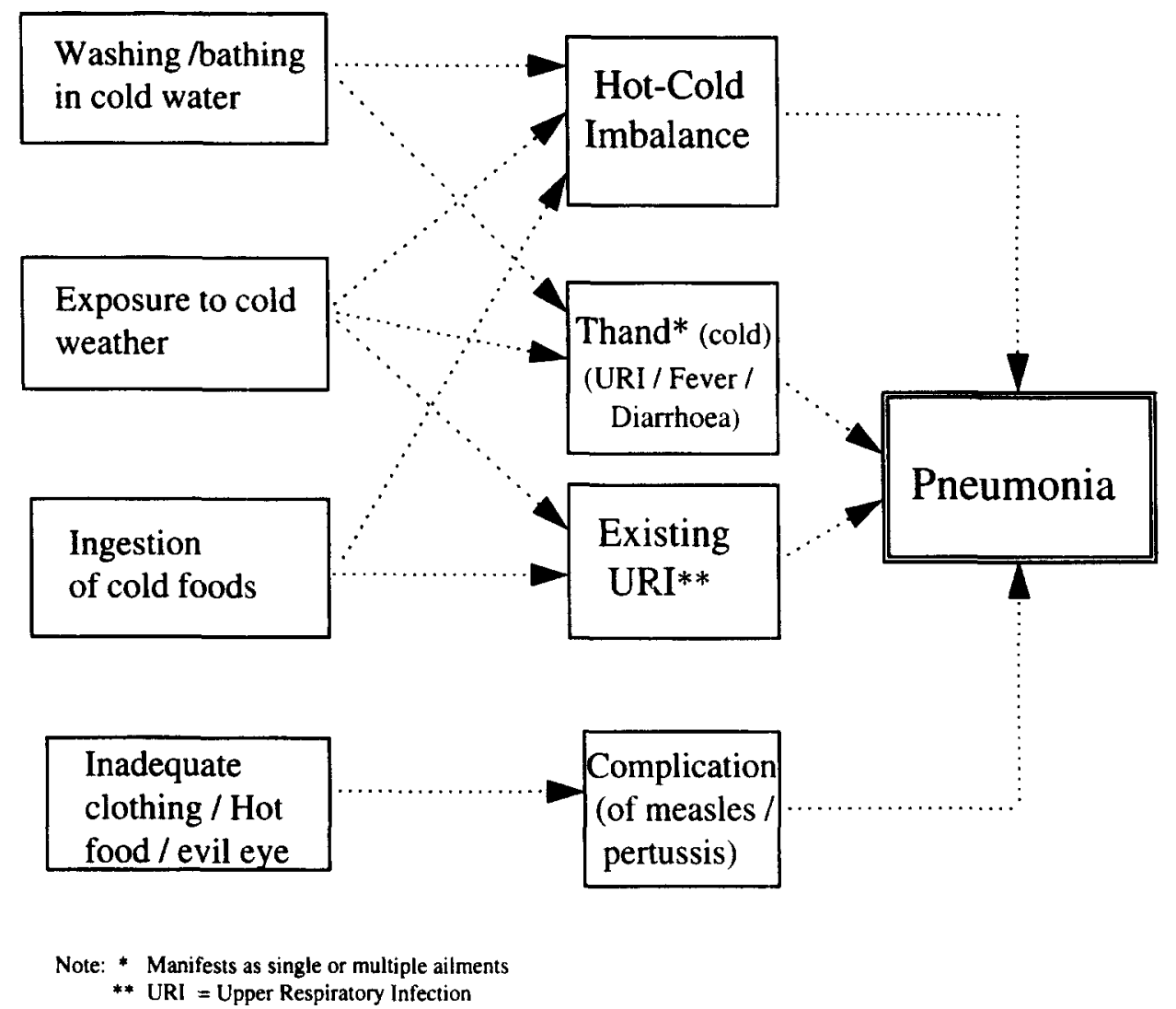

Fig. 1. Concepts of causality of pneumonia in urban squatter settlements of Karachi.

The role of contagion in the transmission of pneumonia was mentioned by only two mothers in one of the focus group discussions. Only in one of the case history interviews was jaraseem (germs) reported as a secondary cause of numonia. In both instances, these were young Mohajir mothers with some years of formal schooling. Knowledge and coverage rates for immunisations were fairly high including for pertussis and measles. However, it is plausible that this could be due to the extensive health education and immunisation campaign over the years through the PHC programme in these two squatter settlements and was not a true reflection of the general situation in the slums of Karachi.

\section{Resort to treatment options}

The dynamics and types of treatment are discussed in detail below. Generally, the sequence of management was to initially start home care and supplement it with allopathic care within one to three days of the onset of symptoms. However, in case of exacerbation of symptoms (such as cough becoming worse or onset of fever with/without respiratory difficulty) not only was outside care (almost exclusively allopathic) sought earlier but there was also a quick turnaround of physicians if no improvement was visible in the first day or so. The general perception about hospital care was that it would only be used as a last option when "jab doctor kehe ke ab case uus ke bas se bahir he [when the doctor says that the case is now beyond him]".

\section{HOME CARE}

Most mothers reported resorting to home treatment in the initial stages of the illness episode. The conditions for which home treatment was commonly used were onset of nazla (rhinorrhoea), zukham (common cold), khansi (cough) and bukhar (fever). The most commonly used home treatments were those that are considered to be garam (hot) or have a direct or indirect garam asar (hot effect). Foods that are considered to be garam include egg yolk given separately or in combination with milk and/or honey. Hot fluids such as kahva (black or green tea) and karra or joshanda (herbal concoctions) were also very commonly given. Some Sindhi women reported use of specific herbs such as jablokati and janam ghutti for preparation of hot fluids. Additional foods that were often reported by Mohajir women were jaifal (nutmeg), javitri (mace), heeng (asafoetida).

Applications commonly used in both the study groups include Balm or Vicks (brand name) and sikai (hot fomentation). In the Sindhi population application of paan (betel) leaves was reported by most mothers. The paan leaves are coated with egg yolk or honey and placed on the child's chest and 
secured in place with a piece of cloth wrapped around the chest at night. The leaves are believed to imbibe the thand from the chest and the egg yolk or honey is supposed to provide a garam (hot) effect and help in seena khulna (decongestion of the chest). Although the use of paan leaves was not reported by Mohajir mothers, application of egg yolk to the child's chest to get rid of the thand were reported as a commonplace practice by them. In some instances, more commonly in Mohajirs than Sindhis, use of heeng (asafoetida) for chest application was also reported.

Chest wrapping was not reported to be a common feature of home treatment in either of the two ethnic groups. Mothers, however, often did resort to covering the child with a blanket or putting on warm clothes or extra layers of clothes especially during the night in order to induce paseena (perspiration) which is seen as a mechanism whereby the body gets rid of the trapped cold. This is in accordance with the findings of the hospital-based study in Rawalpindi (Mull et al., 1994), where only two mothers reported chest wrapping.

In both the Sindhi and Mohajir study groups, very few mothers reported use of medicines kept at home for a numonia episode. The instances where drugs were used without consultation with a physician were mainly for a child with mild fever requiring an antipyretic such as Calpol (brand name of paracetamol), cough or cold syrups and in two cases Septran (cotrimaxazole). Most of the caretakers reported that antibiotics could not be kept for long since they were mostly suspensions (in many cases the antibiotics are packaged as powders requiring mixing with water before use-these liquid preparations are often called suspensions), which the doctors advised to discard within one week of use. However, there were more Mohajir caretakers reporting use of old medicines than their Sindhi counterparts. Probably their relatively higher literacy level made them more confident about use and dosage of old medicines. Similar to Nichter and Nichter's findings in the Philippines (Nichter and Nichter, 1994), mothers often do not try drugs on their own on very young children. Moreover, drugs are only purchased over the counter once they have been prescribed by a physician and proved to be efficacious. The empty bottles are then carefully stored to buy the same drug from the local drug store whenever the need arises again. A positive finding worth mentioning is the minimal use of aspirin by caretakers [aspirin use was reported to be very common in ALRI studies in Egypt (Godomski et al., 1992) and Honduras (Hudelson, 1994)]. The main reason for non-use was the popularity of flavoured syrups and elixirs in general (aspirin is only available in tablet form) and to some extent also the enormous popularity of Calpol [commonly referred to as Maa bachey wali dawai (mother-child medicine) because of the pic- ture of a mother and child on the label] as the drug of choice in fever.

Other measures such as dietary restrictions especially of foods considered to have a cold effect, minimising contact with water and exposure to cold, etc., were all reported as part of efforts to limit disease progression.

\section{OUTSIDE CARE}

All mothers in the focus groups reported seeking consultation with a private "doctor" (both licensed and unlicensed) after one to two days of home treatment or on the same day in situations where there was an exacerbation of illness symptoms. In cases of suspected pneumonia, treatment was sought at the earliest possible time (within hours of manifestation of symptoms) from private doctor(s) Treatment was often sought from the preferred doctor(s) operating within or close to the study area. In situations where a previous experience with a particular doctor located in another area of the city had been particularly favourable, mothers reported going back to the same doctor. Information from the case history interviews corroborated this pattern of resort to treatment (Fig. 2). Five mothers stated to have used home treatment as the initial treatment whereas eleven mothers consulted a private "doctor" as the initial management of the numonia episode. There was no discernible ethnic differential in management strategies. Home treatments such as described above were continued in addition to consultation with, and treatment from, doctor(s).

Most child caretakers expected a quick improvement in the child's condition following one to two doses of allopathic medicines. Improvement was determined by disappearance or decline in fever, easing of breathing and return (partial or complete) of appetite. Resolution of cough and sputum (bulgum/raysha) was recognised to take longer, and the child was considered to be at risk of recurrent pneumonia till the complete disappearance of cough and sputum. The majority of the respondents in the group discussions said they would change doctors if there was no improvement in one to two days. Information from the case history interviews confirmed this attitude. On average, each sick child was seen by a minimum of two "doctors" and in seven of the 16 cases by more than two physicians during the 7-10 days long pneumonia episode. The unfortunate aspect of this expectation of a quick fix was that in very many cases the child received incomplete treatment regimens of two or three very potent antibiotics, and the family lost a considerable sum of money.

The curative services of the PHC programme were minimally utilised in both the study areas. The community, used to physicians pronouncing a diagnosis after minimal history taking and examination 


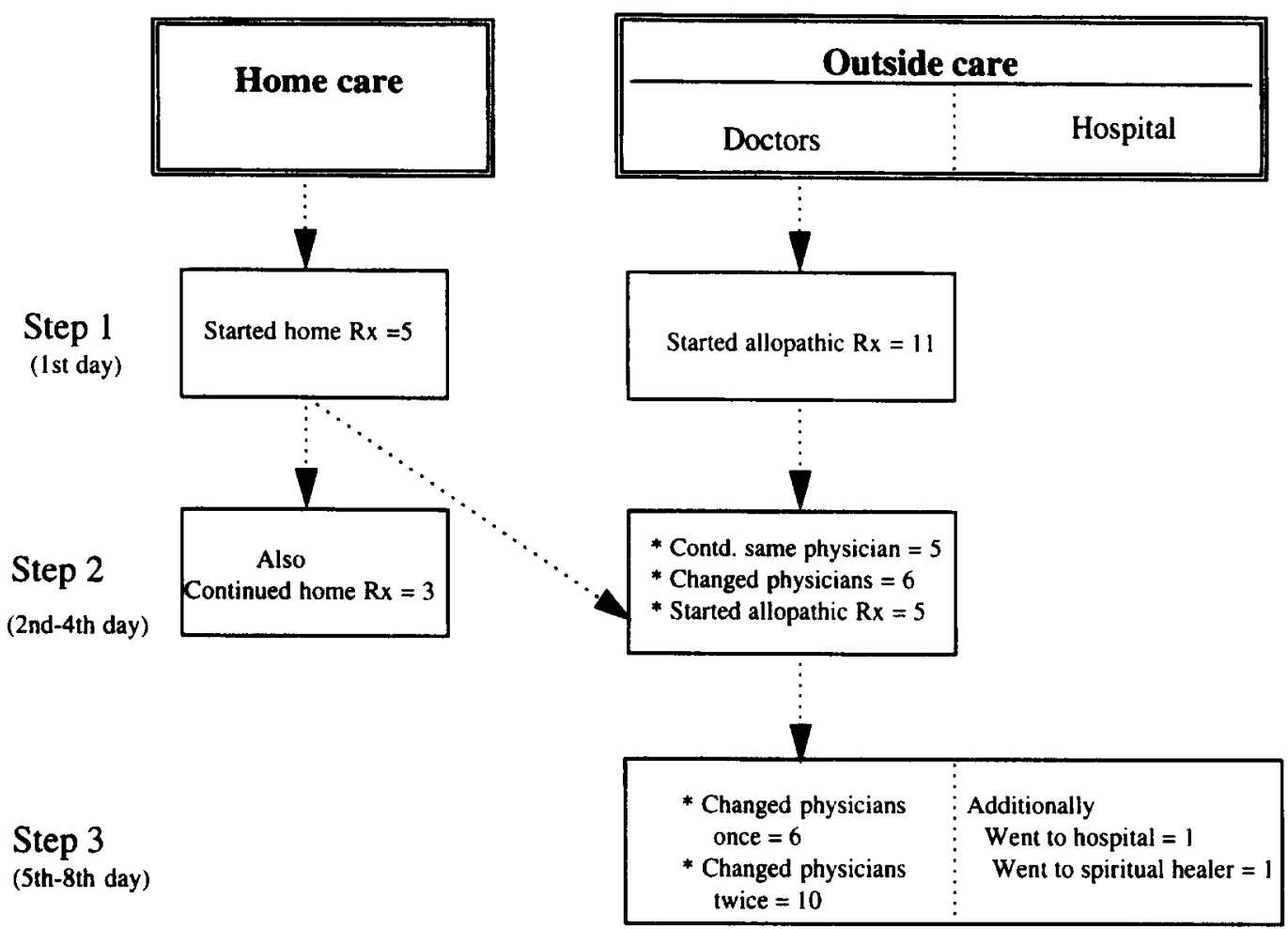

Fig. 2. Resort to treatment options for pneumonia in urban squatters settlements of Karachi $(n=16)$.

and getting a multiple drug prescription (in addition to an injection and some medicines from the doctor's own pharmacy), felt angry and somewhat cheated by the doctors at the PHC centre. The following quote from one of the respondent's typifies the general attitude towards curative care offered by the PHC programme:

they take an hour just to take the history and then more time for examination... it makes me very angry when at the end all I get is a prescription for drugs such as Calpol [paracetamol] which I can easily buy on my own from the drug store... why should I waste my time going there and not a private doctor... the latter takes half the time and gives injections to speed recovery.

As in many other parts of the world (Reeler, 1990), in Pakistan, too, injections continue to be extremely popular for a variety of ailments - both acute and chronic-and across all age groups. The reluctance of the $\mathrm{PHC}$ staff to give injections was seen as "...an attempt to save costly medicines rather than an attempt to curtail the use of unnecessary injections".

Most child caretakers felt that hospital care for pneumonia was only necessary when there was a marked progression of disease symptoms, and the child appeared weak (bohat zayada kamzori). In the case history interviews, only two of the 16 pneumonia cases were referred by the treating doctors to a hospital, and in only one case was the child actually admitted to a hospital. The general consensus was that if need be the child would be admitted to a pri- vate facility rather than the resource-poor public ones.

None of the respondents reported use of hakeems (practitioners of unani medicines) for management of pneumonia (for detailed description of unani medicine in Pakistan see Rahman, 1980). The general perception was that the effect of unani/homeopathic medicines was cold, whereas what was needed in pneumonia were medicines that caused heat. Moreover, respondents felt that pneumonia required fast-acting medicines whereas the usual time for the more "traditional" medicines to show their effect was between two to three weeks. This is contrary to the findings in Bangladesh (Stewart et al., 1994), where mothers reported taking young infants to hakeems as allopathic medicines were considered to be "too strong". The minimal use of more traditional medical systems does not appear to be a peculiarity restricted to these two ethnic groups in the squatter settlements of Karachi. It is a common observation that allopathic care is often preferred, by the urban population in particular, for acute illnesses and the use of traditional medication resorted to for more chronic ailments like hypertension, diabetes, arthritis and so on.

Most mothers did not report resort to spiritual healing from pirs, fakeers or other spiritual healers for pneumonia. A large number of mothers, however, expressed yakeen (faith) in resort to dum (recitation of holy verses from the Quran) by the moulvi (religious expert). Very few mothers reported that they would resort to jharwana (dusting off the 
illness) for pneumonia. A few others felt that a taweez (amulet) from the moulvi might be of help. In reality only one of the case history mothers resorted to spiritual healing. The most common form was dum or getting a taweez at more advanced stages of the disease. Spiritual healing was not resorted to as an exclusive option but rather as a complement to other forms of treatment.

\section{CASE STUDY}

Habiba, a seven-month-old girl, fourth child of Aashi, Sindhi a resident of Chanesar Goth, was diagnosed by the local doctor as suffering from diarrhoea. Aashi attributed Habiba's illness to exposure to thand (cold), on a winter day when Habiba was left out in the verandah of a nearby house where Aashi worked as a domestic aid.

Aashi regretfully reported that soon thereafter, Habiba developed khansi (cough). The cough was non-productive and it seemed as if all the phlegm had accumulated in the chest. Habiba had bund saans (quiet chest) to the extent that her cries were totally muffled. She also developed julab (diarrhoea) ulti (vomiting) and was very baichain (restless).

Aashi thought that Habiba had numonia based on her experience of her elder daughter who had developed similar symptoms when she was a year old. Habiba, however, did not develop severe fever nor had seenay may awaaz (noisy chest) resembling a whistle which characterised the elder daughter's illness. Aashi added that Habiba's disease appeared to be less severe, although she did have vomiting, diarrhoea and appeared very restless. Aashi's belief in her diagnosis was further strengthened by her own personal experience of having saans (respiratory illness/rapid breathing), which had been cured with medication.

Aashi sought treatment from a "doctor" one day after Habiba developed cough. Concurrently she also started home treatment because she believed that desi ilaaj (folk/indigenous treatment) would lead to an earlier improvement in Habiba's condition. She, however, refrained from going to a hakim or "homoeopath" as she had no faith in their treatment. For three consecutive days she made a roti (flat thin round bread) with crushed ajvain (plant name carum ajowan) and gur (molasses) rolled into the flour. She cooked one side of the roti and left the other side katcha (uncooked). The katcha side was applied at night to the ribs and secured with a light cloth wrapping. The logic of leaving one side uncooked was to allow the thand (cold) to be imbibed by the wet flour. It would also allow for the hot effect of ajvain and gur to open the chest which Aashi described as seena khulna. This opening of the chest would allow the trapped phlegm to come out through vomiting.

Habiba's illness, however, progressed from mild cough to rapid breathing and chest indrawing.
Aashi, therefore, sought consultation from another "doctor" who gave an injection, some medicine from his clinic and also prescribed some. The doctor did not diagnose the child as suffering from pneumonia, but instead said that Habiba had pani kee kami (dehydration) and advised that the child be taken to Jinnah Hospital (a public tertiary care facility about two kilometres away). Aashi expressed her inability to go to the hospital as she had other children who needed to be looked after as well. The doctor, therefore, prescribed Nimkol (Pakistani ORS).

The treatment was continued for one week but there was no improvement. Aashi changed physicians again and went to another "doctor". She was convinced that Habiba had numonia. By the end of the week Habiba's condition deteriorated rapidly. Aashi's mother-in-law and sister-in-law advised that the child should be taken to a private hospital as the care is much better at a private facility. The "doctor" at the nearby big private hospital prescribed "Gentacin" (gentamicin) injection along with syrup "Amoxil" (both antibiotics) and cough syrup. By the next day, Habiba was extremely lethargic and did not take any food. The mother in panic went to another "doctor" who gave "Kaoplex" (anti-diarrhoeal), "Cotrimoxazole" (antibiotic), "Phenergan" (anti-emetic) and an injection of "Marzine" (antipyretic). Habiba, however, died the next day.

During the condolence visit by the research team, Aashi expressed her deep disappointment at the failure of "doctor(s) to diagnose Habiba's pneumonia". She was convinced that the child did not receive the right treatment or else she would not have died.

\section{Decision-making, female autonomy and financial con- siderations}

The mothers reported to be the primary decisionmakers regarding outside care in the group discussions. In reality, too, in over two-thirds of pneumonia cases, mothers were the key decision-makers for seeking outside care, with grandmothers making the decision in less than a quarter of the cases (in two of the three cases the mother was out of town and the grandmother had the primary responsibility of taking care of the child). Interestingly, in the group discussions there was a strong denial of any limitations of mobility or autonomy that would delay seeking outside care. Almost all the respondents echoed the response of one of the participants: "When the child is sick, and the father is away at work, the child's treatment is the mother's responsibility. In fact if I do not take my child to the doctor, my husband would get extremely upset with me about my negligence". There appeared to be genuine resentment when we probed the issue further, and an elderly respondent retorted "What age do you [the investigators] live in... The old 
days are gone when there were some men who would not allow their women to go out in emergencies... Fortunately, there are no such men in our communities now". However, some of the younger women did concede that they did take a female friend or relative along, but it was more because of their own shyness rather than any restrictions imposed by the husband or his family. There appeared to be very little ethnic differentials in perceived female autonomy or reported decisionmaking dynamics. Contrary to our expectations, based on educational differences between the two groups, the Sindhi caretakers appeared to be as autonomous and confident of seeking outside care as their Mohajir counterparts.

Similarly, we found that despite economic hardships, child caretakers attempted to seek the best possible care for children sick with pneumonia, especially if they sensed the illness could be life threatening. The respondents were unanimous in their stand that "a woman (mother) would go to any lengths of borrowing money to save her child". In none of the case history interviews did the respondents cite the lack of money as a factor in delaying treatment. Borrowing money in times of crisis was a norm in these communities and people readily shared resources being acutely aware that the next time round it might be their turn to borrow.

In contrast to the findings of Stewart et al. (1994) in rural Bangladesh, in our study not only did women appear to be main decision-makers, they felt comfortable seeking outside care on their own, even in the absence of family support and/or endorsement (husbands/mothers-in-law). This could well have to do with the availability of quite a few health practitioners within walking distances in the urban slums in Karachi. However, we did find some reluctance to go to hospitals alone especially among younger respondents. Unlike Bangladesh (Stewart et al., 1994) or Rawalpindi (Mull and Mull, 1994), the issue is not so much a restriction of female mobility, as there is no strict observance of pardah in these communities, but more a matter of someone taking care of other young children and/or of shyness in dealing with a cumbersome and confusing system of locating either the right outpatient clinic or getting through the hassles of emergency room admission procedures. And it is in such situations that the presence of a male member or an experienced female relative becomes important in deciding whether the child should be hospitalised or not.

\section{Gender bias}

There was no difference in pneumonia cases by sex of the child in the two communities. However, among infants (nine out of the total 16 cases), $78 \%$ were females, and all except one belonged to Sindhi households. A review of the birthweights and nutritional status information, maintained in the records at the PHC centres, revealed that all the female cases of pneumonia had normal birthweights but developed undernutrition (based on weight for age criterion) in the first six to eight months of life. Although our sample is too small to make any conclusive argument, the large number of female infants with pneumonia does make us wonder whether some form of subtle discrimination against the girl child begins soon after birth, thus making her more vulnerable to undernutrition and infections in infancy. Our suspicions are further reinforced by the findings of an earlier study that found the risks of undernutrition to be twice as high for female infants as compared to male infants in squatter settlements of Karachi (Thaver et al., 1990).

With regards to prompt seeking of outside care for children suffering from pneumonia we did not find any gender bias which is contrary to the findings of other studies conducted in Pakistan (Ahmad, 1990; Mastro et al., 1991; Hunte and Sultana, 1992; Mull et al., 1994). In fact in most cases (as illustrated by the case study), mothers invested considerable time and money in seeking appropriate allopathic care for female children which was in no way different from their management strategies for male children. The reasons for an apparent lack of gender bias in health seeking behaviour in our study was perhaps the ease of access to health practitioners in the squatter settlements of Karachi. It is plausible that caretakers, when faced with the prospect of longer distances and more complex decisions, are more anxious about male children whereby they receive medical attention earlier and more often than female children.

\section{DISCUSSION AND IMPLICATIONS}

Contrary to the popular belief that most of the pneumonia mortality is attributable to poor maternal knowledge of signs and symptoms, we found that recognition of pneumonia was universal in both the ethnic groups, with a good correspondence between local terms and their biomedical equivalents especially for danger signs such as chest indrawing, although terminology for associated signs and symptoms did vary by maternal ethnicity and age. Similar findings have been reported by other ethnographic studies and it appears that mothers respond to a set of danger signals based on the severity of perceived symptoms rather than perception of an illness category (Gittelsohn et al., 1991; Godomski et al., 1992; Charaly, 1992; Khallaf, 1992). It may, therefore, be more fruitful to adapt health education messages around the specific illness terms and severity indicators commonly used by child caretakers. Moreover, although fever is not reliably associated with pneumonia (Harris et al., 1991), our results show that in both 
the ethnic groups the onset and/or increase in the intensity of fever was the most common triggering mechanism for seeking outside care. Hence it is important that maternal focus and apprehensions of fever should be incorporated into the ARI programme to make it more credible.

The recognition of rapid breathing (unprompted/ prompted) as an important danger sign for pneumonia was limited in our study population in general, and among the Sindhi caretakers in particular. This contrasts with the findings of Mull et al.'s (Mull et al., 1994) work on pneumonia cases in a hospital setting in Rawalpindi, where mothers often mentioned fast breathing when probed in detail about the child's condition. However, beyond recognition, the accurate counting of respiratory rate is also an issue in its own right. Research in very many parts of the world has shown that not only mothers but even trained health workers have difficulty in counting respiratory rate. Although there are no easy solutions especially in settings where the majority of women are illiterate and innumerate, we feel that a concerted effort is needed, first, at the community level to make mothers realise the importance of fast breathing with and without accompanying fever and, second, to expedite the large-scale manufacture and distribution of affordable and easy to use battery-operated time counters or similar devices.

The folk aetiology of pneumonia is also at variance with the biomedical concept of contagion and airborne transmission. Programme planners as well as managers, therefore, need to take into account the historical perspective of the widely held notion of "humoural imbalance" as the main causal mechanism in occurrence of pneumonia. This belief system, which derives its roots from the ancient system of humoral medicine proposed by Hippocrates and Galen (Shah, 1966) coupled with influences from the ayurvedic (Fendall, 1981) and unani (Rahman, 1980) medicine, is prevalent throughout the different strata of Pakistani society. Although we found a preponderance of the hot-cold imbalance as a causal mechanism in the Mohajir community, the perception was not uncommon among the Sindhi respondents. Furthermore, this finding when coupled with earlier work on pneumonia perceptions among the Punjabi population (Kundi et al., 1993; Rehman et al., 1994; Mull et al., 1994) goes to show that the belief in humoral imbalance is deeply entrenched and transcends cultural/geographic boundaries in Pakistan. The national ARI programme thus needs to incorporate this belief system into its training programme. This in no way implies negation of the need to educate caretakers about pneumonia transmission, but in our experience of community work in Karachi, we have often found the community more willing to accept and adopt new health messages when they find them linked to their own belief system. One such potential link for the ARI programme is through health messages that reinforce the importance of treating early signs and symptoms of pneumonia through home therapies (Gove, 1990) already in use, such as the use of hot fluids (which would greatly minimise the rash use of expensive cough mixtures for uncomplicated cough), keeping the child warm, etc. Additionally, mothers need to be reminded about the importance of adequate nutrition in URI, and the current practice of withholding most foods should be discouraged. Moreover, although some caretakers, more commonly Mohajir caretakers, appeared to link undernutrition with increased risk of an URI turning into ALRI, the high prevalence of moderate to severe undernutrition in these slum settings, particularly in Chanesar Goth, requires this point to be reiterated time and again.

The biggest failing is not of perceptions of causation or symptomatology but of appropriate and effective management of pneumonia at community level. The problem is twofold. Firstly, mothers' unrealistic expectations of a quick cure leads them to change physicians often, with a sick child receiving two or three incomplete regimens of very potent antibiotics. Although we had expected the Mohajir caretakers, by virtue of their relatively better educational status, to be less inclined to switch physicians, the results of our study found little difference in illness management between the two ethnic groups. Such a lack of distinction could well have something to do with the second aspect of the problem-the poor quality of care available in these slum areas. More than half of the "doctors" functioning in these low income areas do not have medical qualifications. Their practice is largely based on the medical experience gained from some years of work as nurse-assistants in public or private hospitals and/or dispensers of private general practitioners. These "doctors" not only perpetuate attitudes about a quick fix cure by limiting the treatment to a daily basis, but also reinforce such expectations by resorting to a polypharmacy approach. Indeed it is not uncommon to see them prescribing an antipyretic, an anti-malarial, a broad-spectrum antibiotic (both injectable and oral), cough mixture and multivitamin syrup on the very first visit of a child with high grade fever. The task of the national ARI control programme in such a situation is indeed a formidable one. Nonetheless, it would be well-served by extending its training on standardised care management for ARI, to unlicensed practitioners, in addition to arranging training for GPs in private practice. Our decade-long experience of working in the slums of Karachi shows that in order to change community expectations of what constitutes quality care, health managers need to develop an effective two-prong strategy: of educating the community and its health care practitioners simultaneously. 
Lastly, we feel that although our study provides useful insights into ethno-specific illness terminology, folk aetiology and resort to treatment for the two main ethnic groups in Sindh, there are major differences in the availability of basic health services in different parts (desert vs irrigated districts) of rural Sindh. The dynamics of decision-making and seeking outside care, we suspect, may not only differ from urban to rural, but may also vary within different rural districts of Sindh. More studies are, therefore, needed to understand the management of childhood pneumonia in a variety of settings in the rural areas. There is also a need to initiate actionoriented research that tests the effectiveness of simple health messages in local languages based on the available body of data.

Acknowledgements-Financial support for the research was provided by the Applied Diarrhoeal Disease Research Project at Harvard University through a cooperative agreement with the U.S. Agency for International Development (USAID). The authors gratefully acknowledge the contribution of the following individuals: $\mathrm{Dr}$ Pamela Hunte for assisting with the development of the project proposal; Dr Johannes Sommerfeld for his expert advice during data collection and analysis; and John Simon for administrative support. The authors also wish to thank Sabira Latif, Asia Masud, Shenaz Giovani and the staff of the PHC teams of Orangi and Chanesar Goth.

\section{REFERENCES}

Aga Khan University (1990) Analysis of the Quantitative Indicators: Report of Urban PHC Programme. MIS Unit, Dept of Community Health Sciences, Karachi.

Aga Khan University (1991a) 1990 Deaths: CHS Led Field Sites-Report of the Urban PHC Programme. MIS Unit, Dept of Community Health Sciences, Karachi.

Aga Khan University (1991b) Analysis of the Quantitative Indicators: Report of Urban PHC Programme. MIS Unit, Dept of Community Health Sciences, Karachi.

Aga Khan University (1992) 1991 Deaths: CHS Led Field Sites-Report of the Urban PHC Programme. MIS Unit, Dept of Community Health Sciences, Karachi.

Ahmad, A. (1990) Gender Differentials in Access to Health Care for Pakistani Children, Vol. 1. UNICEF, Islamabad.

Ahmed, T. et al. (1992) Pakistan Demographic and Health Survey 1990-91. National Institute of Population Studies, and the Institute for Resource Development Macro International, Columbia, MD.

Bang, A. R., Bang, O. T., Sontakke, J., Solanki, R., Wargantiwar, P. and Kelzarkar, P. (1990) Reduction in pneumonia mortality by means of community-based intervention trial in Gadchiroli, India. Lancet 336, $201-$ 206.

Charaly, D. (1992) Focussed ethnographic study - an ARI research tool: views and practice-FES in Bolivia. $A R I$ New's 23, 4

de Tejada, S. S. (1990) Popular notions of ARI in Guatemala and Ghana. Unpublished manuscript, Department of Anthropology, University of Arizona, Tuscon.

Dyal, A. D. and Bhattacharyya, K. (1994) The Marath "taskonomy" of respiratory illnesses in children Medical Anthropology 15, 395-408.

Fendall, N. R. E. (1981) Ayurvedic medicine and primary health care. Trop. Doctor 11, 81-85.
Gittelsohn. J., Sillah, B. and Sanneh, K. M. (1991) Ethnographic Study of Acute Respiratory Infections in the Gambia. Dept of International health, Johns Hopkins School of Public Health, Baltimore

Godomski, A., Khallaf, N. and Black, R. (1992) The signs and symptoms of acute ARI in Egyptian children. Final report/prepublication draft

Gove, S. (1990) Coughs and colds: remedies for young children. ARI News 18, 2-3.

Harris, M.et al. (1991) Clinical signs of pneumonia in children. Lancet 338, 928-930.

Hudelson. P. (1994) The management of acute respiratory infections in Honduras: a field test of the Focused Ethnographic Study (FES). Medical Anthropology 15 , 435-446.

Hunte, P. A. and Sultana, F. (1992) Health seeking behaviour and the meaning of medications in Balochistan Pakistan. Social Science \& Medicine 34, 1385 1397.

Karim, M. S. (1987) Findings from Communitv Survers in Karachi. Aga Khan University, Department of Community Health Sciences, Karachi.

Khallaf, N. (1992) Focussed ethnographic study -an ARI research tool: views and practice--FES in Egypt. $A R I$ News 23, 3 .

Khan, S. R., Jalil. F., Zaman, S., Lindblad, B. S. and Karlberg, J. (1993) Early child health in Lahore. Pakistan: X. Mortality. Acta Paediatrica, Supplement 390, 63-78.

Kresno, S., Harrison, G. G., Bambang, S. and Reingold, A. (1994) Acute respiratory illnesses in children under five years in Indramayu. West Java, Indonesia: a rapid ethnographic assessment. Medical Anthropology 15, 425-434.

Kundi, M. Z., Anjum, M., Mull, D. S. and Mull, J. D. (1993) Maternal perceptions of pneumonia and pneumonia signs in Pakistani children. Social Science \& Medicine 37, 649-660.

Marsh, D.. Majid, N., Rasmussen, Z., Mateen, K. and Khan, A. A. (1993) Cause-specific child mortality in a mountainous community in Pakistan by verbal autopsy. Journal of the Pakistan Medical Association 43, 226-229.

Mastro, T. D., Ghafoor, A., Nomani, N. K., Ishaq, Z. Anwar, F., Granoff, D. M., Spika, J. S., Thornberry, C. Facklam, R. R. (1991) Antimicrobial resistance of pneumococci in children with acute lower respiratory tract infection in Pakistan. Lancet 337, 156-159.

Mechanic, D. (1962) The concept of illness behaviour Journal of Chronic Diseases 15, 189-194.

Mull, D. S. and Mull, J. D. (1994) Insights from community-based research on child pneumonia in Pakistan Medical Anthropology 15, 335-352.

Mull, D. S., Mull, J. D., Malik, M. Z. and Anjum, M. (1994) Mothers' perception of severe pneumonia in their own children: a controlled study in Pakistan. Social Science \& Medicine 38, 973-987.

Nichter, M. and Nichter, M. (1994) Acute respiratory illness: popular health culture and mother's knowledge in the Philippines. Medicine and Anthropology 15, 353-375.

Rahman, M. (1980) Urban and rural medical systems in Pakistan. Social Science \& Medicine 14D, 283-289.

Reeler, A. V. (1990) Injections a fatal attraction. Social Science \& Medicine 31, 1119-1125.

Rehman, G. N., Qazi, S. A., Mull, D. S. and Khan, M A. (1994) ARI concepts of mothers in Punjabi villages: a community-based study. Journal of the Pakistan Medical Association 44, 185-188.

Selwyn, B. J. (1990) The epidemiology of acute respiratory infection in young children: comparison of finding from several developing countries. Review of Infectious Diseases 12(8), 870-888

Shah, M. H. (1966) The General Principles of Avicenna's Cannon of Medicine. Naveed Clinic, Karachi. 
Stewart, K. M., Parker, B., Chakraborty, J. and Begum, H. (1994) Acute respiratory infections (ARI) in rural Bangladesh: perceptions and practices. Medical Anthropology 15, 377-394.

Thaver, I., Ebrahim, G. J. and Richardson, R. (1990) Infant mortality and undernutrition in urban squatter settlements of Karachi. Journal of Tropical Pediatrics 36, 135-140.

Tuapasi, T. E.et al. (1990) Patterns of acute respiratory tract infections in children: a longitudinal study in a depressed community in Metro Manila. Review of Infectious Diseases 12(8), 940-949.

UNICEF (1994) State of the World's Children. Oxford University Press, New York.
Vathanopass, Ket al. (1990) A community-based study of acute respiratory infections in Thai children. Review of Infectious Diseases 12(8), 957-965.

Wilson, R. P. and Kimane, I. (1990) Mother's perception of ALRI: a case study in Lesotho. In ALRI and Child Survival in Developing Countries, ed. A. Godomski. John Hopkins University, Baltimore.

World Health Organisation (WHO) (1990) Acute Respiratory Infections. WHO, Geneva.

World Health Organisation (WHO) (1993) Focused Ethnographic Studies of ARIs. ARI/93.2, WHO, Geneva.

Zaman, S., Jalil, F., Karlberg, J. and Lindblad, B. S. (1993) Early child health in Lahore, Pakistan: VI. Morbidity. Acta Paediatrica, Supplement 390, 63-78. 